\title{
Turistificação do Espaço e Exclusão Social: a revitalização do bairro de Jaraguá, Maceió - AL, Brasil
}

\author{
Touristification of Space and Social Exclusion: \\ revitalization of Jarazuá's district, Macei -.. AL, Brazil
}

\section{Daniel Arthur Lisboa de Vasconcelos}

\begin{abstract}
RESUMO: Considera-se "turistificação" o (re)ordenamento ou a (re)adequação espacial em função do interesse turístico, cujo processo ocorreu em Maceió-AL., no bairro de Jaraguá, influenciado por financiamentos originados do Banco Interamericano de Desenvolvimento - BID e Banco do Nordeste do Brasil - BNB. Esses capitais foram concretizados em ações por meio do Programa de Ação para o Desenvolvimento do Turismo do Nordeste - PRODETUR-NE, que visa ao desenvolvimento do turismo nessa região. Com base na situação atual de uma comunidade periférica de pescadores, por meio de revisão bibliográfica e de visitas in loco, constatou-se que a turistificação e a revitalização desse bairro ocorreram de forma excludente para a população local, nos moldes da atual fase do modo capitalista de produção.
\end{abstract}

PALAVRAS-CHAVE: turistificação; PRODETUR-NE; comunidade periférica excluída.

ABSTRACT: "Touristification" refers to the (re)qualification of space to meet the tourist industry interests. This has taken place in Maceió, the capital city of the Alagoas state, northeast Brazil, through the revitalization project of the Jaragua district. The revitalization project, which is based on the 
Northeast Tourism Development Program - PRODETUR-NE, is funded by the Inter-American Development Bank through Brazil's Northeast Bank. This study examined the current situation of a community that is located in the Jaraguá district. The study results give evidence that the touristification and revitalization of the area has excluded this community from the benefits resulting from the touristification project.

KEYWORDS: touristification; PRODETUR-NE; excluded community.

\section{Introdução}

O fenômeno turístico pode ser definido sob vários enfoques. As abordagens variam desde aspectos técnicos, acadêmicos, jurídicos, econômicos até holísticos e sistêmicos, que tentam definir o fenômeno da maneira mais completa possivel. Cruz (2000:7) afirma que o fenômeno

[...] surge como uma atividade econômica organizada em meados do século XIX e, àquele tempo, utilizava-se integralmente, de infra-estruturas criadas em razão de outros usos do território. De lá para cá, entretanto, a atividade deixa, paulatinamente, de ser uma usuária passiva dos territórios para tornar-se mais um agente condicionador de seu (re)ordenamento.

Desde as primeiras viagens organizadas, nas proximidades de século XIX (dando início ao chamado Grand Tour), até hoje, aconteceram várias mudanças. O dinamismo das sociedades, nesse sentido, é fator crucial nas transformações efetuadas no que hoje denominamos Turismo (Cruz, 2003).

O turismo é uma prática social que envolve deslocamento de pessoas pelo território e que tem como seu principal objeto de consumo o espaço (Cruz, 2003). Outro fato que não podemos ignorar é que a atividade turística, como fenômeno essencialmente social, é atrelada ao modo de produção ${ }^{2}$ vigente. Nesse sentido, Moesch (2000:15) ressalta que

[o] Turismo é processo humano, ultrapassa o entendimento como função de um sistema econômico. Como um processo singular, necessita de

2. Modo de produção é a maneira pela qual uma sociedade produz, utiliza e distribui seus bens e serviços; exemplos de modos de produção: primitivo, escravista, asiático, feudal, socialista e capitalista (Oliveira 2001). ressignificação às relaçōes impositivas, aos códigos capitalísticos e aos valores, colocados como bens culturais.

Contemporaneamente, o regime ou o modo de produção dominante em nossa sociedade ocidental é o sistema capitalista que, como sabemos, é baseado na incessante busca pela apropriação de lucro e rentabilidade.

Nesse regime, os meios de produção (capital financeiro, máquinas, fábricas, fontes de energia) são dependentes da propriedade privada (Durozoi \& Roussel, 1996), trazendo consigo um dos maiores problemas desse sistema, o da exclusão social, que se manifesta nas atividades atreladas ao modo de produção, a exemplo da turística.

Aos olhos de alguns, o turismo implica, apenas, deslocamento. Contudo, o fenômeno tem grande potencial para gerar impactos no espaço que, visto de forma mais ampla, vai além da paisagem, considerando todas as inter-relações que nela podem ocorrer. Dentro dessa ótica, ocorre o processo denominado por váriosestudiosos do turismo de turistificação-Knafou (2001), Banducci Jr.e Barretto (2001) e Cruz (2003), entre outros.

Analisando os trabalhos desses autores, formulamos um conceito para o termo turistificação, que em nosso entendimento consiste no (re)ordenamento ou na (re)adequação espacial em função do interesse turístico. É uma interação entre fixos (território, paisagens etc.) e fluxos (capital, pessoas, padrões e valores culturais) que influencia as diferentes esferas da organização socioespacial.

Em nossa análise, consideramos que esse processo ocorreu na cidade de Maceió, capital alagoana, mais especificamente em um histórico e boêmio bairro, o Jaraguá3.

A turistificação do Jaraguá, a exemplo do que vem ocorrendo em várias áreas do Nordeste brasileiro, foi influenciada, em grande parte, por um processo de financiamento originado de uma das grandes instituições financeiras mundiais: o Banco Interamericano de Desenvolvimento - BID, por intermédio do Banco do Nordeste do Brasil - BNB, que funciona(ou) como uma agência captadora de capital transnacional, em nível regional.

Esses capitais foram concretizados em ações por meio do Programa de Ação para o Desenvolvimento do Turismo do Nordeste - PRODETUR-NE, que possui como objetivos expressamente formulados a promoção do desenvolvimento do setor turístico da região Nordeste, de forma sistêmica, a partir da disponibilização de infra-estrutura de apoio ao turismo; e o avanço no processo de melhoria da qua-

3. Ver localização do bairro no Anexo 1. 
lidade de vida da população fixa inserida nas áreas a serem beneficiadas, aumentando, assim, as condições para a atração de visitantes (Banco do Nordeste, 2003).

Porém, na prática, o que temos observado é que o modelo de turismo proposto pelo PRODETUR-NE reproduz o neoliberalismo ${ }^{4}$, como acontece em outros setores da economia nacional.

De acordo com Castrogiovanni (2000), o território é o espaço apropriado por determinado grupo, e o valor de consumo desse território atende às tendências do mercado - e nem sempre às necessidades sociais. Acreditamos que tal fato ocorreu em Jaraguá.

Diante do exposto, nossa proposta é trazer reflexões sobre alguns aspectos, quais sejam: o PRODETUR-NE (fator crucial para a mais recente onda de turistificação no Nordeste brasileiro), suas influências locais e a sua relação com uma comunidade que vive em um espaço "periférico", ao lado do Porto de Jaraguá, na cidade de Maceió.

\section{O PRODETUR-NE: algumas proposições e ações institucionais no bairro de Jaraguá, Maceió - AL}

Durante as três últimas décadas, a revolução tecnológica da informação originou um novo tipo de capitalismo (também referido como globalização), profundamente diferente daquele formado durante a Revolução Industrial ou daquele que emergiu após a Segunda Guerra Mundial. As principais características dessa nova ordem são: o cerne global de suas atividades econômicas; inovação, geração de conhecimento e processamento da informação como principais fontes de produtividade e competitividade; e sua estruturação ao redor de fluxos de financiamento ${ }^{5}$.

O atual estágio do capitalismo e as decorrentes transformações ocorridas em nossa sociedade contemporânea são frutos dessa nova ordem mundial, que também pode ser representada pelo surgimento das empresas multinacionais e o fomento dos movimentos internacionais de capitais.

Com a mundialização das relações capitalistas e a construção de bases internacionais para sua consolidação, surgiram as grandes instituições financeiras

4. Modelo centrado no capitalismo hegemônico e corporativista, o qual desconsidera as questōes sociais conjunturais e, sobretudo, as estruturais (Rodrigues, 2001).

5. CAPRA, F. As conexöes ocultas: ciência para uma vida sustentável. Palestra apresentada no Fórum Ambiental petrobrás em Aracaju-sF, no dia 8 de agosto de 2003. mundiais, como o Fundo Monetário Internacional - FMI e o Banco Mundial (Oliveira, 2000).

De acordo com Oliveira (2000:254), o Banco Mundial engloba importantes instituições financeiras internacionais, como o Banco Internacional de Reconstrução e Desenvolvimento - BIRD:

[...] o BIRD e o seu similar americano BID (Banco Interamericano de Desenvolvimento), são instituiçōes que articulam açōes supranacionais nos diferentes países de modo a adotar políticas nacionais que permitam maior integração dos mesmos à comunidade financeira internacional. Em outros termos, isso significa que essas organizaçōes cumprem a função de articular os interesses do capital monopolista multinacional e das elites nacionais, numa espécie de "grande governo econômico-financeiro internacional" do mundo capitalista. Garantem dessa forma a gestão mundial da economia capitalista mundializada.

Como já mencionamos, o desenvolvimento do turismo dá-se de acordo com a conjuntura socioeconômica em que a atividade ocorre, e o PRODETUR-NE surge nesse contexto de articulação entre os capitais multinacionais e os interesses das elites nacionais.

Nessa direção, o início da década de 1990 foi marcado pela implementação da política neoliberalista no Brasil. Nesse período, o país passou por uma grave crise político-econômica, que causou grande decréscimo no Produto Interno Bruto - PIB. Diante desse quadro, o desenvolvimento do turismo foi apontado como uma salvação para muitos dos problemas econômicos, sendo concebido o PRODETUR-NE (Rodrigues, 2001).

O Programa surgiu por meio de uma iniciativa dos governadores dos estados do Nordeste, sendo formalizado por meio da portaria conjunta da Superintendência de Desenvolvimento do Nordeste - SUDENE e do Instituto Brasileiro de Turismo - EMBRATUR (portaria no 01/91 de 29 de novembro de 1991), com o propósito de desenvolver o turismo integrado na região Nordeste (e norte do Estado de Minas Gerais), estimulando o aumento do nível de empregos e a geração de renda por meio do fortalecimento do fluxo turístico (Rodrigues, 2001).

Os objetivos específicos do PRODETUR-NE foram elencados em torno do aumento do turismo receptivo, aumento da permanência dos turistas no Nordeste, indução de novos investimentos em infra-estrutura turística e geração de emprego e renda com a exploração direta e indireta da atividade turística (Tecnologia e Consultoria Brasileira S.A., 1996).

O objetivo central do programa seria induzir investimentos em infra-estrutura turística, buscando suprir as deficiências de infra-estrutura básica e dos 
serviços públicos. Isso se daria nas “[...] áreas em expansão turística, onde a capacidade do estado não acompanhou a demanda por tais serviços" (BNB, 1995 apud Cruz, 2000:111). rigido

No entanto, como indica Rodrigues (2001:155), o programa está sendo di-

[...] para o fortalecimento do turismo receptivo internacional, calcado em projetos de grande envergadura (modelo mexicano) financiados por capitais transnacionais, nos quais a tendência à exclusão das comunidades locais é preocupante.

É nesse modelo que a região Nordeste do Brasil se insere no processo de globalização do turismo.

Em Alagoas, mais especificamente em Maceió, a turistificação do bairro de Jaraguá ocorreu nesse contexto: capitais transnacionais, grandes projetos e exclusão social.

O PRODETUR-NE subordina(va)-se a quatro níveis de gestão: nacional (EMBRATUR), regional (SUDENE, CTI-NE e BNB), estadual e municipal. Vale ressaltar, novamente, que o Banco do Nordeste do Brasil - BNB funciona(ou) como uma agência captadora de capital transnacional em nível regional, por meio desse programa.

A Unidade Executora Municipal - UEM, em Maceió, foi uma exceção como órgão gerenciador dos recursos do PRODETUR-NE, pois os outros estados onde o programa se fez presente tinham unidades executoras estaduais. A justificativa para isso foi o fato de o Estado de Alagoas não poder assumir a contrapartida do BID, por conta da sua situação político-econômica na época. Por isso, a prefeitura de Maceió assumiu essa contrapartida, criando a UEM. Em 1996, foi assinado o subempréstimo de US\$ 44 milhões, fato que, de certa forma, feriu os critérios do BID, pois foi realizado excepcionalmente para o município de Maceió (UEM/PNM, 1996 apud Costa, 1998).

Em 1996, por meio do Decreto Estadual no 36.902, de 9 de maio, foi criada a Unidade Executora Estadual - UEE, atendendo às exigências do convênio firmado entre o Governo Estadual e o Banco do Nordeste (Costa, 1998).

Segundo a Tecnologia e Consultoria Brasileira S.A. (1996),

[...] a partir de 1992, a prefeitura Municipal de Maceió iniciou sua participação no PRODETUR ALAGOAS, como integrante do Programa à [sic] nível estadual, entendendo a sua importância para o município. Neste sentido vários estudos - planos e projetos - foram desenvolvidos pelos órgãos municipais em atendimento à demanda do BI/BNB.
Os projetos e ações elencados para o município de Maceió contemplariam o abastecimento de água; a limpeza urbana; a melhoria das vias urbanas; o esgotamento sanitário; a reurbanização; o re-assentamento de famílias; a revitalização do patrimônio histórico-cultural; a restauração e revitalização de edifícios e praças de Jaraguá; o enterramento das redes aéreas de energia e telefonia; e o fortalecimento institucional em âmbito municipal (Tecnologia e Consultoria Brasileira S.A., 1996).

Especificamente para o bairro abordado neste texto, foi proposto o Projeto de Revitalização do Bairro de Jaraguá, que propunha

[...] a transformação da área urbana do bairro de Jaraguá provendo-a de todas as condições para o desenvolvimento de atividades de lazer, comércio, turismo, cultura, exposições, entre outras, à comunidade de Maceió e aos seus turistas (Projeto de Revitalização do Bairro de Jaraguá, 2003).

Por causa de seus pitorescos aspectos histórico-culturais, Jaraguá foi considerado um bairro com grande potencial para atrair demandas turísticas e, na década passada, foi iniciado o seu processo de revitalização, com base no financiamento por capitais transnacionais (empréstimos na ordem de milhões de dólares), seguindo a tendência de outros centros históricos no Nordeste, como os de São Luís-MA, João Pessoa-PB, Recife-PE e Salvador-BA.

\section{0 fomento de um "não-lugar" em um centro histórico de Maceió-AL}

Jaraguá é um lugar rico em aspectos histórico-culturais. Para muitos historiadores, ele deu origem à cidade de Maceió, no século XVII. Porém, há quem afirme que a cidade originou-se a partir de uma vila de pescadores, situada próxima ao porto, e desenvolveu-se a partir dessas atividades. Os historiadores são unânimes, apenas, em afirmar que não há uma certeza sobre a origem de Maceió (Costa, 1982).

As primeiras habitações definitivas em Jaraguá pertenceram a uma família portuguesa. Com o surgimento de mais residências e casas comerciais após 1820, o bairro tornou-se um ativo centro comercial, cheio de companhias de navegação, bancos, restaurantes e, até mesmo, cabarés. No entanto, o que mais marcou a história econômica dessa região foram os antigos armazéns, denominados trapiches. 
No alvorecer do século xx, com toda a movimentação portuária, o Jaraguá passou por intenso progresso industrial, comercial e cultural. $\mathrm{Na}$ segunda metade desse mesmo século, o lugar tornou-se famoso por ser uma zona de meretrício freqüentada pelos boêmios da cidade.

Durante a década de 1980, no entanto, a decadência começa a ficar evidente. Problemas de infra-estrutura, transportes e serviços assolaram a localidade. As más condições de tráfego na maioria das ruas e a falta de conservação dos casarões evidenciavam o aspecto de abandono e a urgente necessidade de ações revitalizadoras.

Grande parte do casario ainda existente no lugar foi construída nos séculos XVIII, XIX e início do xx. Hoje, a principal rua do bairro, a Sá e Albuquerque, com seus trapiches, sobrados e prédios históricos, é a maior herança do passado desse bairro boêmio.

Como foi mostrado, em anos recentes o bairro foi submetido a um projeto de revitalização por meio do PRODETUR-NE, que tinha como alguns de seus principais objetivos o incremento do turismo e a melhoria das condições de vida da população local. Vamos considerar que esse projeto foi o norteador do processo de turistificação local, que consistiu num reordenamento socioeconômico.

Algumas obras foram executadas, como o melhoramento das calçadas e a criação dos calçadões, a recuperação de praças e de prédios históricos - como o Palácio do Comércio (sede da Associação Comercial de Maceió) -, bem como a construção do Centro Cultural e de Exposições. Outras parecem ter sido esquecidas, como a recuperação da Vila dos Pescadores de Jaraguá. Talvez possamos relacionar a isso o que Banducci Jr e Barretto (2001:18) nos ensinam quando afirmam que o "[...] processo de turistificação (transformação em lugar turístico) dá-se ao sabor do mercado, de empreendedores isolados, quase sempre sem planejamento" [...].

De fato, o que vemos é que com a intensificação do uso turístico em determinada porção do espaço geográfico, surgem, multiplicam-se e concentram-se objetos com função referente ao desenvolvimento turístico, como é o caso dos equipamentos de prestação de serviços, de restauração e da infra-estrutura de lazer (Cruz, 2003).

Acreditando na recuperação da dinâmica local, empresários investiram em equipamentos de lazer e de apoio ao turismo, concentrando esses investimentos na rua Sá e Albuquerque. Tais empreendimentos, agregados ao novo visual decorrente da restauração de alguns principais monumentos da rua, atraíram novamente os maceioenses e os visitantes (turistas e excursionistas) para o lazer noturno no Jaraguá.

Entretanto, por uma simples observação da dinâmica diária local, podemos facilmente perceber que os processos de revitalização e de turistificação não lograram êxito. Isso pode ser observado, por exemplo, pelo baixo fluxo de turistas que visitam o bairro. Além disso, o fluxo de residentes, hoje, está aquém do esperado, pois apesar de não existirem dados concretos sobre o fato, se observarmos a quantidade de empreendimentos de lazer noturno e de equipamentos de restauração que fecharam suas portas nos últimos anos, teremos um dado que demonstra, no mínimo, certo desinteresse pelo bairro. Dados da Associação dos Bares e Estabelecimentos de Jaraguá demonstram que, desde o início da revitalização até junho de 2003, cerca de 23 estabelecimentos haviam fechado (Acioli, 2003).

Contudo, seguimos o pensamento de Cruz (2000), e acreditamos que a importância do turismo resida menos nas estatísticas (que mostram parcialmente seu significado) e mais na sua capacidade de condicionar o (re)ordenamento de territórios para a sua realização.

Esse insucesso do projeto de reestruturação do Jaraguá está na falta de um planejamento adequado para a implementação dos projetos elencados para a área, a exemplo do que veremos adiante neste trabalho.

De acordo com Hall (2001:25), "a característica mais importante do planejamento é o fato de estar voltado para o futuro". Pelo que se pode constatar, as ações em Jaraguá tiveram características imediatistas, ou seja, não foram pensadas para o longo prazo.

Além disso, os problemas sociais do bairro continuam evidentes, bem representados pelas subcondições de vida dos moradores da "favela de Jaraguá", situada ao lado do cais do porto, nas proximidades da área de lazer noturno do bairro.

Problemas como falta de segurança e pedintes nas ruas, entre outros, contribuíram para repelir a demanda pelo lazer noturno no bairro; a maioria dos empreendimentos na área de alimentos e bebidas fechou em um curto espaço de tempo, e os que ainda restam, lutam contra as condições adversas que tendem a levá-los à falência (Acioli, 2003), pois estes, em sua maioria, dependiam e dependem do espaço público para a prestação de seus serviços, que eram (ou deveriam ser) agregados à "imagem do lugar".

A maior parte das casas de lazer que se manteve é a que explora ambientes internos, fechados, bolhas ambientais ${ }^{6}$ sem um maior contato com a realidade local. Não podemos nos esquecer, nessa direção, que

6. Segundo Luchiari (2000), essa concepçāo foi desenvolvida por Boorstin (1964) e utilizada por diversos autores. Refere-se a espaços alienados de seu contexto (Cruz, 2000), também conhecidos como "nāo-lugares" (Augé, 1994), pseudo-acontecimentos, hiper-realidades ou simulacros (MacCannell, 1976; Krippendorf, 1989; Featherstone, 1994; Urry, 1996 apud Luchiari, 2000). 
o lugar é produto das relações humanas, entre homem e natureza, tecido por relaçōes sociais que se realizam no plano do vivido, o que garante a construção de uma rede de significados e sentidos que são tecidos pela história e cultura civilizadora produzindo a identidade. Aí o homem se reconhece porque aí vive [...] (Carlos, 1999:28).

Augé (1994) considera a história, a relação social e a identidade aspectos comuns aos verdadeiros lugares. A revitalização de Jaraguá foi, e vem sendo, realizada sem preocupação com essa noção de lugar. Distante da realidade que cerca o bairro, o projeto de revitalização fez-se isolado da imagem, da realidade social e das potencialidades culturais e históricas do lugar.

Enfim, observa-se que o bairro de Jaraguá tornou-se um não-lugar. Conforme Gallero (2004), o não-lugar é destituído de identidade, relações ou história. Lembramos, em relação a isso, a afirmação de Carlos (1999:28):

O espaço produzido pela indústria do turismo perde o sentido, é o presente sem espessura, quer dizer, sem história, sem identidade; neste sentido é o espaço do vazio. Ausência. Não-lugares. Isso porque o lugar é, em sua essência, produção humana, visto que se reproduz na relação entre espaço e sociedade, o que significa criação, estabelecimento de uma identidade entre comunidade e lugar, identidade essa que se dá por meio de formas de apropriação para a vida.

Gallero (2004) afirma que, no lugar, a transformação do cotidiano e o distanciamento dos visitantes fomentam a configuração do não-lugar; tal fato nega as características de identidade dos povoadores e cria um sentimento de estranhamento. "Aqui, o grave não é a mudança, mas, sim, o fato dessa mudança surgir por imposição externa” (Gallero, 2004:40). Nesse sentido, percebemos a indiferença com a Vila dos Pescadores.

A estandartização da paisagem (especialmente da arquitetura) e a exclusão social são algumas características desse processo de apropriação turística (Cruz, 2000), tal qual vem ocorrendo em Jaraguá. A autora afirma, também, que existem grandes dificuldades para eliminar usos anteriores nas áreas onde se fez presente o PRODETUR-NE. "Daí decorre uma constante tensão que paira sobre esses espaços, resolvida, em parte, pelo policiamento dessas áreas” (Cruz, 2000:145). Em Jaraguá, essa tensão é uma constante, afinal existe uma periferia com inúmeras necessidades incrustada no centro histórico revitalizado.

Devemos ressaltar, também, que o termo revitalização significa "dar mais vitalidade", sendo assim, entendemos que excluir uma comunidade do seu pró- prio contexto socioespacial não é algo que dê vitalidade a qualquer projeto que pretenda ser sustentável ${ }^{7}$.

Sabemos que já existem turistas, especialmente estrangeiros, que desejam conhecer o estilo de vida periférico no Brasil. Exemplo disso são as visitas realizadas por muitos grupos à famosa favela da Rocinha, no Rio de Janeiro (Cruz, 2003). Sabe-se que essa demanda ainda não foi detectada no destino Maceió, entretanto, mesmo se tivesse, poderíamos ainda questionar se esse tipo de turismo pode ser "saudável" para um núcleo receptor.

Corrobora com isso a idéia de Castrogiovanni (2000:24), de que "os turistas, papel que assumimos quando estamos em movimento no espaço, fazem parte dos fluxos. Eles não são meros observadores desse espetáculo, mas parte dele".

Quanto ao modelo de desenvolvimento turístico local, não acreditamos que seja sustentável e gere bons frutos a longo prazo. Esse modelo é muito bem descrito por Serpa (2002:168):

Um turismo de alienação, indiferente à identidade do lugar [...] o surgimento de novos enclaves turísticos, criando cenários, para "varrer para debaixo do tapete" os problemas urbanos e sociais advindos do "padrão periférico" de ocupação - prática comum no chamado "turismo de massa".

\section{Exclusão: a "periferia" em Jaraguá e seus problemas}

Empréstimos com organismos internacionais multilaterais, ações de revitalização e a tentativa de atrair visitantes não livraram o Jaraguá de uma das maiores mazelas do sistema capitalista: a exclusão. Trata-se da exclusão pela indiferença com uma comunidade. Lá residem pescadores há pelo menos várias décadas. Essas pessoas deparam-se com o belo e a imponência dos prédios restaurados para a apreciação de outros, que vêm de fora. Isso contrasta com a visão das dificuldades diárias de quem vive em um "lugar periférico", gerando uma paisagem antagônica.

Consta no Projeto de Revitalização do Bairro de Jaraguá:

[...] em 1942 foi inaugurado o cais do porto [...]. Com a construção do cais houve o acúmulo de areia entre o mesmo e a rua Sá e Albuquerque. O

7. O relatório da Comissão Mundial de Meio Ambiente e Desenvolvimento - WCDE (1987:49 apud Hall, 2001:20), define: "Desenvolvimento sustentável é aquele que atende às necessidades do presente sem comprometer a possibilidade de as gerações futuras atenderem às próprias necessidades". 
assoreamento distanciou o mar, gerando amplo espaço onde apareceu a mais nova rua de Jaraguá [...]. Além dessa rua surgiu também uma favela, que aos poucos foi se instalando à beira mar, no espaço criado, hoje Vila dos Pescadores (Projeto de Revitalização do Bairro de Jaraguá, 2003).

A exclusão dessa comunidade é fomentada até mesmo pela falta de um nome que propicie identidade ao lugar. Não existe consenso acerca da denominação. Alguns moradores a chamam "favela de Jaraguá"; outros, "vila dos pescadores".

Para evitar problemas de conceituação do que venha a ser uma vila ou uma favela, a definiremos como uma "periferia", termo que

[...] explicita áreas localizadas fora ou nas imediaçōes de algum centro. Todavia, muitas áreas afastadas dos centros das cidades não são entendidas, atualmente, como periféricas. O termo absorveu uma conotação sociológica, redefinindo-se. Dessa forma, "periferia" hoje significa também aquelas áreas com infra-estrutura e equipamentos de serviços deficientes, sendo essencialmente o locus da reprodução sócio-espacial da população de baixa renda (Serpa, 2002:161).

Jaraguá não é um "bairro periférico" no espaço físico urbano. Contudo, com base no conceito de Serpa (2002), podemos considerar que lá existe uma "periferia social".

Essa periferia está inserida numa área à beira-mar entre o porto de Jaraguá e alguns armazéns. Podemos estimar que aproximadamente mil pessoas ${ }^{8}$ vivem em um lugar com péssimas condições sócio-econômico-ambientais, em contraste com a circunvizinhança de casas noturnas de lazer, restaurantes, instituições, monumentos e prédios históricos revitalizados.

Com a Lei Municipal no 3.536, de 23 de dezembro de 1985, foi instituído o Código de Urbanismo da Cidade de Maceió. Esse documento determinou que diversas áreas do município fossem enquadradas na categoria de Zonas Especiais, as quais são "referentes a espaços territoriais que, devido às suas características, exigem estudos e orientação especial para o disciplinamento de seu uso, ocupação e urbanização" (Prefeitura Municipal de Maceió, 1995).

8. Em um censo realizado por estudantes e professores da Faculdade de Alagoas em 2003, concluiuse que havia 921 pessoas residentes no local. Em um projeto arquitetônico para a construção de uma nova vila de pescadores (infelizmente nāo executado), datado de 1996, estimava-se cerca de dois mil moradores, correspondentes a 400 famílias. Na época, detectou-se que, "desta populaçāo, $35,8 \%$ vive da atividade pesqueira, em condiçōes de muita pobreza e com uma elevada taxa de analfabetismo e graves problemas de saúde e mortalidade infantil [...]”. (Pascual Arquitetos Associados, 1996/1997).

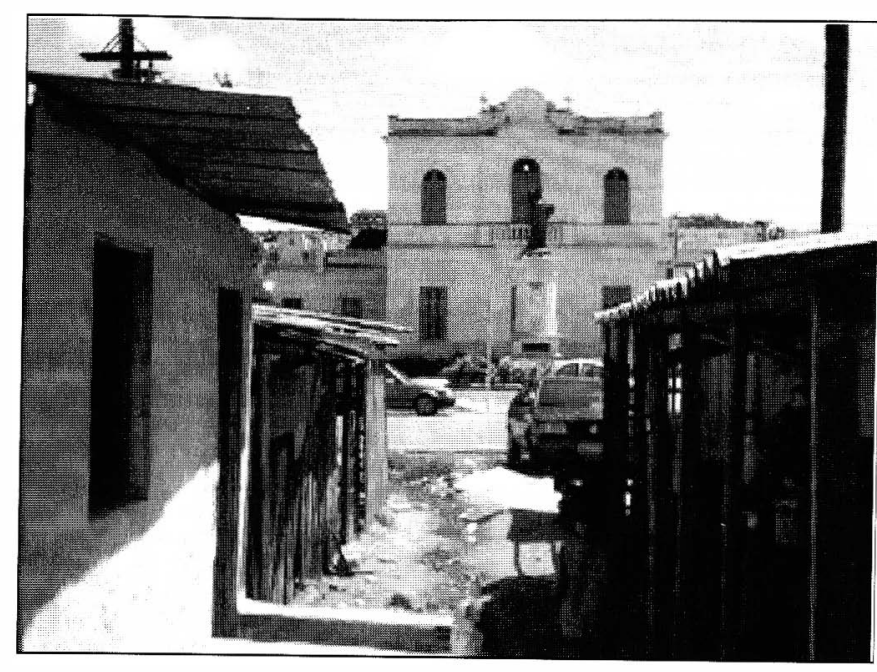

Figura 1. Contraste visto por quem vive na periferia. Prédios históricos revitalizados versus infra-estrutura precária

Fonte: Arquivo pessoal, 2004

Em 1996, um decreto municipal de Maceió’ instituiu, em seu artigo $1^{\circ}$, que grande parte do Jaraguá se tornaria Zona Especial de Preservação - ZEP: “[...] constituída pelo sítio histórico do Jaraguá, considerada área de interesse histórico e arquitetônico, tendo sua preservação dirigida à vocação turística, de lazer e de cultura" (Maceió, 1996). Segundo esse mesmo documento, no seu art. $1^{\circ}-\mathrm{v}$, a área da Vila dos Pescadores é um Setor de Preservação Ambiental - SPA, sendo "[...] considerada de interesse social por ser constituída de construções ocupadas por populações de baixa renda, cuja atividade principal é a pesca” (Maceió, 1996).

Apesar dessas considerações do documento, não se observa, até o presente momento, nenhuma prática de preservação ambiental e interesse social. A Vila dos Pescadores diferencia-se de seus entornos não somente pela precariedade de sua configuração espacial, com grandes deficiências de infra-estrutura básica, equipamentos e serviços urbanos essenciais. A exclusão está presente em todos os aspectos na vida de seus moradores que carecem de educação, saúde, participação política e outras condições para viver com um mínimo de dignidade.

\footnotetext{
9. Decreto municipal nº 5.569, de 22 de novembro de 1996 .
} 


\section{Os projetos para a periferia}

Um dos subprojetos do Projeto de Revitalização do Bairro de Jaraguá deveria contemplar diretamente a Vila dos Pescadores, como está descrito no documento.

O projeto consiste na urbanização da área, com a permanência da população (pescadores), no mesmo espaço onde atualmente vivem (favela), através da melhoria na sua infra-estrutura, implantando o sistema de saneamento básico, energia elétrica, abastecimento d'água, pavimentação, drenagem, construção de residências térreas e sobrados acabando com a sub-habitação e proporcionando beneficiamentos gerais.

A concepção do projeto levou em consideração os vários fatores econômicos e sociais, permitindo que a comunidade beneficiada possa obter em seu próprio espaço todas as condiçōes de uma sociedade auto-sustentável. Após implantado, o projeto integrará a área do complexo turístico do bairro de Jaraguá, permitindo não só a sociedade local se beneficiar, como também os turistas que visitarem Maceió, através da criação de uma arquitetura pitoresca, com equipamentos como o mercado modelo, o cais e as habitaçōes.

Também eram previstos alguns outros projetos e ações elencados para Maceió dentro do PRODETUR-NE. Seguem alguns tópicos sobre os detalhamentos e componentes desses projetos e ações apresentados.

Vila dos Pescadores e área do Porto: implantação e melhoria de infra-estrutura urbana, serviços e equipamentos públicos. Finalidades: reverter o quadro de insalubridade nas áreas residenciais de baixa renda e dotar a população dos serviços públicos urbanos; recuperar a imagem urbana da área do porto, adequar toda a área ao projeto de desenvolvimento turístico do bairro de Jaraguá.

Bairro de Jaraguá: remoção das famílias que não dependem do porto e da pesca para locais a serem determinados em outros bairros de Maceió. Finalidade: recuperar a Colônia de Pescadores e melhorar a qualidade de vida da população que permanecerá no local (Tecnologia e Consultoria Brasileira S.A., 1996).

Podemos perceber que essas ações deveriam contemplar a comunidade local com abastecimento de água potável, coleta seletiva de lixo, saneamento, infraestrutura, serviços urbanos etc. Tais condições poderiam ocasionar uma melhoria na qualidade de vida dos residentes, principalmente para a população de baixa renda. Mas tudo isso está muito distante da realidade local.
Em 1996 foi proposto o projeto arquitetônico para a "nova" Vila dos Pescadores, o qual foi elaborado para aproveitar as características espaciais da área, com o aproveitamento possível do que já existia e a reestruturação do uso, dimensionamento e características. A proposta fundamental desse projeta seria a “[...] auto-sustentação da comunidade, predominando a produção e comercialização do pescado, seus derivados e artesanato em geral, através da reorganização global do espaço" (Pascual Arquitetos Associados, 1996/1997).

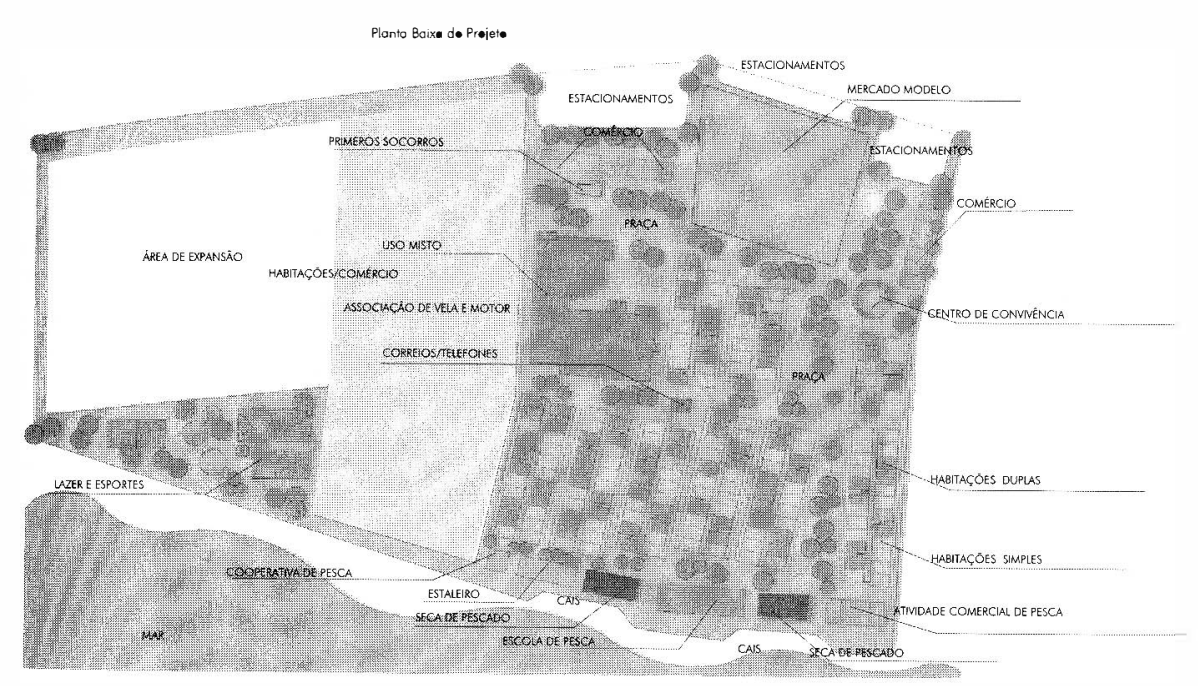

Figura 2. Planta baixa do projeto para a "nova" Vila dos Pescadores

Fonte: Pascual Arquitetos Associados, 1996/1997.

Os autores do projeto acreditavam que a nova situação resgataria a dignidade perdida das diversas gerações de moradores da vila; no entanto, questões políticas locais impediram a concretização dessa proposta.

Em um dos documentos base para o projeto de revitalização de Jaraguá, a população de baixa renda residente no bairro foi identificada como ponto obrigatório a ser atingido em planos e programas de reurbanização, nesse caso: “[...] esta deverá ser relocada, sempre que possível para dentro da própria área” (Prefeitura Municipal de Maceió, 1995:35). Contudo, os fatos divergiram dessas propostas. O que pudemos constatar, por meio de informações dos moradores locais, foi a transferência de pessoas que dependem da pesca para lugares relativamente distantes de sua fonte de sustento: o mar. 
Enfim, observamos que, apesar de todas as propostas, a realidade local continua uma realidade periférica. A área está superpopulosa por causa das péssimas condições de habitação e da falta de espaço físico para a grande quantidade de moradores; a maioria das casas e dos barracos não tem água potável; a falta de saneamento culmina em esgoto a céu aberto; o lixo gerado é acumulado no local, acarretando graves problemas ambientais e sanitários; não existe uma infra-estrutura mínima capaz de gerar qualidade de vida; além de inúmeros outros problemas de ordem sócio-econômico-ambiental que merecem maiores estudos.

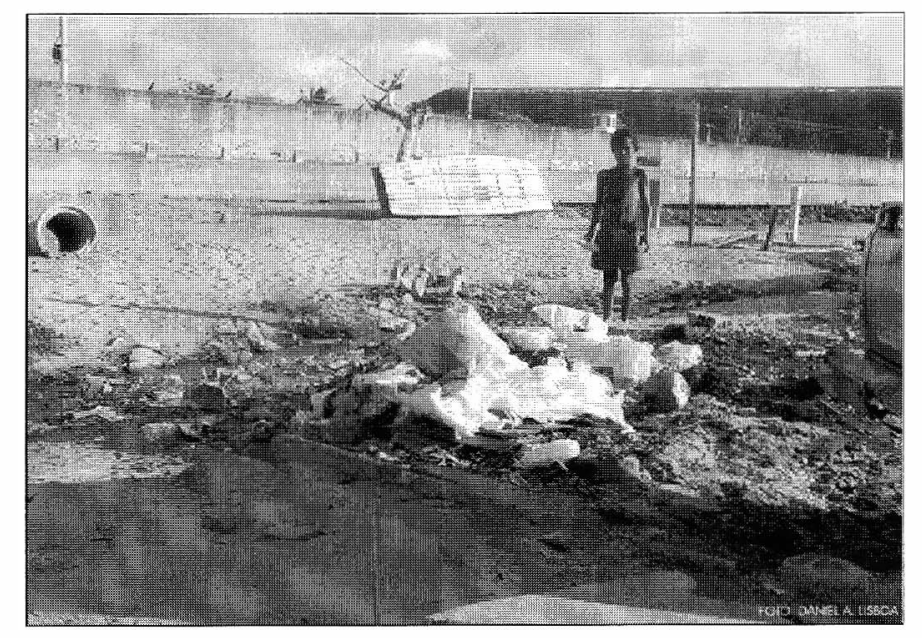

Figura 3. O lixo e o esgoto acumulam-se em diversos locais

Fonte: Arquivo pessoal, 2004

A realidade encontrada é que, após os investimentos da primeira etapa do PRODETUR-NE em Maceió, a situação para a comunidade local pouco mudou. Essa comunidade não foi integrada ao projeto de revitalização e à turistificação de Jaraguá, da mesma forma que a administração pública não conseguiu controlar o descompromisso com a população local e as falhas de planejamento, resultando, tudo isso, numa sucessão de insucessos. Hoje, a Vila dos Pescadores está no esquecimento, bem como os seus moradores, que vivem "isolados" e segregados dentro de seu próprio habitat.

\section{Considerações finais}

Após pesquisa documental, revisão bibliográfica e visitas in loco, pudemos constatar que os processos de turistificação e revitalização em Jaraguá ocorreram de forma excludente, nos moldes da atual fase do modo capitalista de produção.

O turismo, como atividade social, mas com grande interface econômica, não deixa de ser influenciado por esse contexto, que se expressa muito bem no Brasil, no Nordeste e no Estado de Alagoas com a onda de turistificação ocasionada pelo PRODETUR-NE.

Esse programa tem fomentado grandes transformações espaciais para o uso turístico, porém, estas têm transformado o espaço em mercadoria. Tal fato incentiva a formação de "não-lugares", destituídos de identidade, sendo ainda características destes, as paisagens forjadas e a exclusão social.

Consideramos a exclusão social a pior conseqüência desse modelo de turistificação, fundamentando essa afirmação com o exemplo da Vila dos Pescadores de Jaraguá (Maceió-AL), uma "periferia" sem identidade e carente de alguém que olhe de perto seus problemas e necessidades.

Desse modo, deixamos aqui as seguintes reflexões: Qual a finalidade de gerar um lugar turístico com a comunidade local insatisfeita? Como conceber a turistificação sem respeitar a dignidade humana, sem levar em conta as necessidades das populações de baixa renda? Não seria esse um exemplo de entrave para o verdadeiro desenvolvimento turístico sustentável?

Por fim, fica a proposta para a realização de estudos que contemplem a interface turistificação do espaço versus exclusão, ou seja, de pesquisas referentes aos impactos de projetos de desenvolvimento turístico no local abordado ou em outras comunidades de baixa renda, excluídas, distantes de usufruírem os benefícios que o desenvolvimento turístico pode ocasionar. 


\section{ANEXOS}

\section{Maceí}

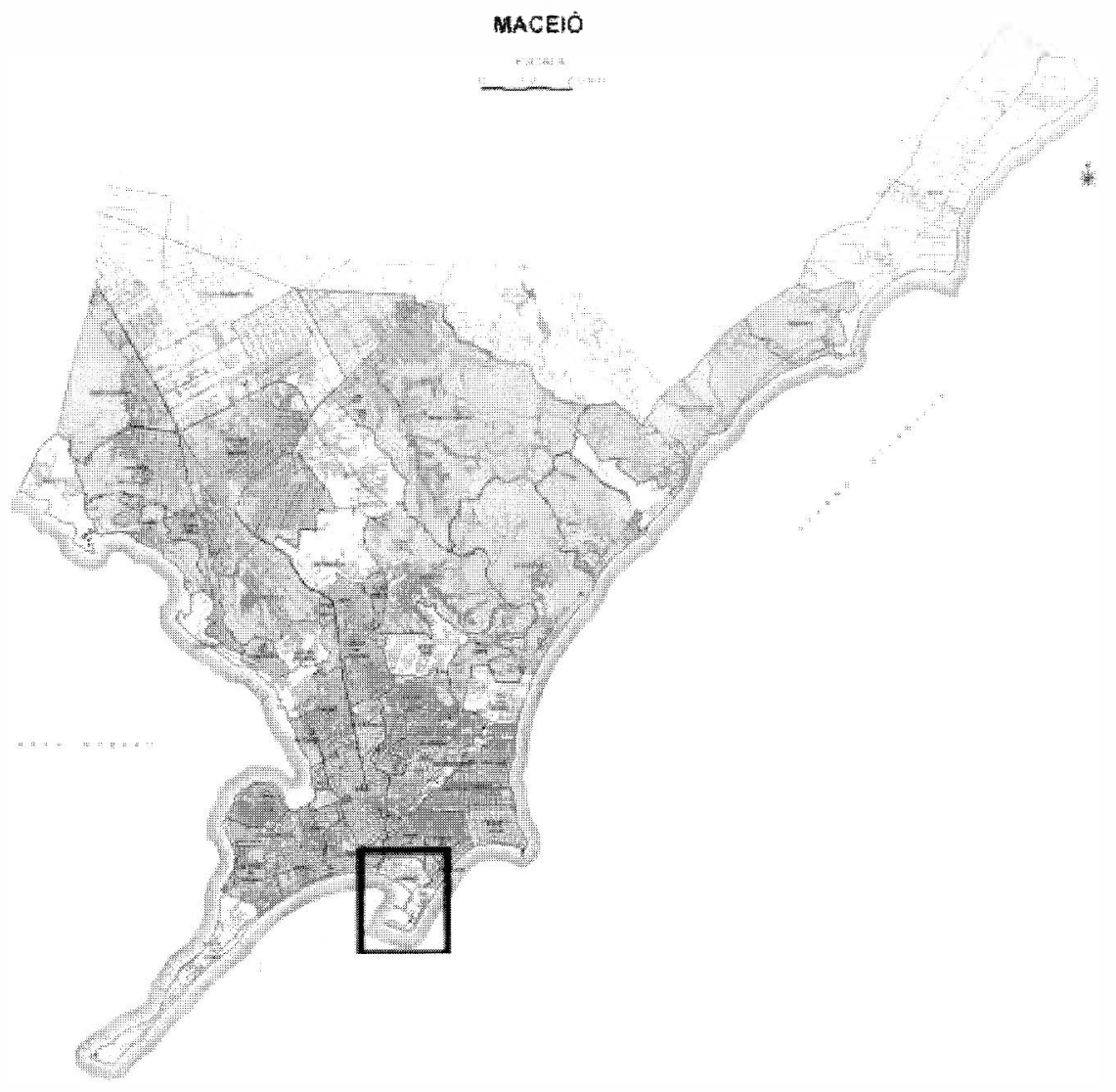

1. Localização do bairro de Jaraguá na cidade de Maceió - AL

Fonte: LGA; GEM; CCEN \& UFAL, 2004. Adaptação: Daniel Arthur Lisboa de Vasconcelos.

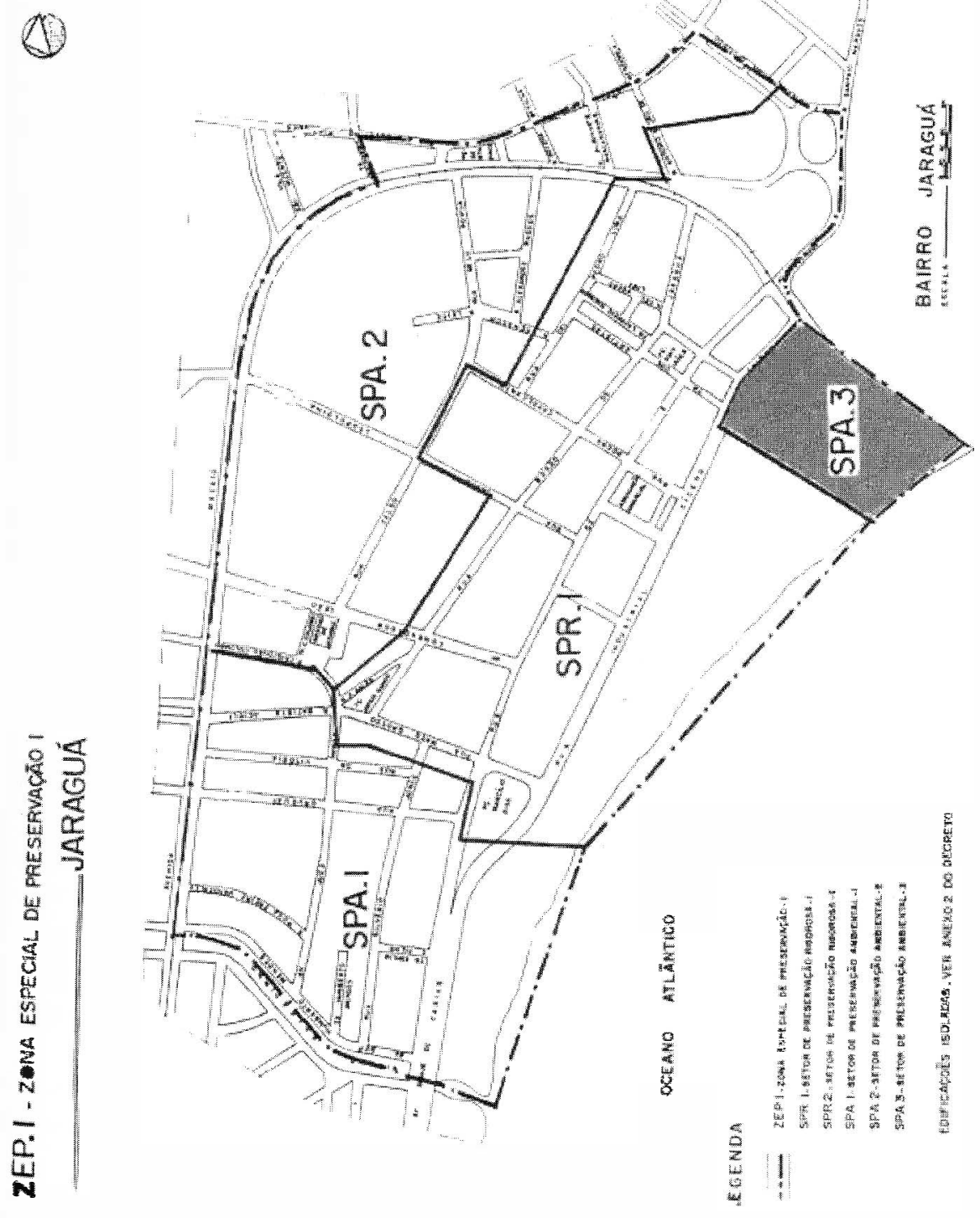

2. Localização da "região periférica” de Jaraguá (região escura)

Fonte: Maceió, 1996. Adaptação: Daniel Arthur Lisboa de Vasconcelos. 


\section{Referências bibliográficas}

ACIOLI, G. 2003. Jaraguá Acabou. Jornal Primeira Edição, Maceió, 30 jun.

ALAGOAS. 1994. Programa de Desenvolvimento Turistico de Alagoas - PRODETUR-AL: estratégia e plano de ações estaduais. Maceió: Governo do Estado de Alagoas, jun.

AUGÉ, M. 1994. Não-lugares: introdução a uma antropologia da supermodernidade. Campinas-sP: Papirus.

BANCO DO NORDESTE. 2003. PRODETUR-NE. Disponível em: <http://www.banconordeste. gov.br/prodetur/default.htm>. Acesso em 25 ago.

BANDUCCI JR., Álvaro \& BARRETTO, Margarita (Orgs.). 2001. Turismo e identidade local: uma visão antropológica. Campinas-sp: Papirus.

CASTROGIOVANNI, A. C. 2000. Turismo e ordenação no espaço urbano. In: CASTROGIOVANNI, A. C. (Org.). Turismo urbano. São Paulo: Contexto. p. 23-32.

COSTA, F. B. 1998. Para onde vai o turismo de Maceió? Uma discussão sob a ótica da sustentabilidade. Maceió: Programa Regional de Desenvolvimento e Meio Ambiente - PRODEMA.

COSTA, C. 1982. Maceió. 2. ed. Maceió: SERGASA.

CARLOS, A. F. A. 1999. O turismo e a produção do não-lugar. In:YÁZIGUI E.; CARLOS A. F. A \& CRUZ, R. C. A. (Orgs.). Turismo: espaço, paisagem e cultura. 2. ed. São Paulo: Hucitec.

CRUZ, R. C. A. 2003. Introdução à geografia do turismo. 2. ed. São Paulo: Roca.

2000. Politica de turismo e território. São Paulo: Contexto.

DUROZOI, G. \& ROUSSEL, A. 1996. Dicionário de filosofia. 2. ed. Campinas, SP: Papirus.

GALLERO, A. L. 2004. O lugar e o não-lugar no turismo. In: GASTAL, S. \& MOESCH, M. M. (Orgs.). Um outro turismo é possivel. São Paulo: Contexto. p. 36-42.

HALL, C. M. 2001. Planejamento turístico: políticas, processos e relacionamentos. São Paulo: Contexto.

KNAFOU, R. 2001. Turismo e território: por uma abordagem científica do turismo. In: RODRIGUES, A. A. B. (Org.). Turismo e geografia: reflexões teóricas e enfoques regionais. 3. ed. São Paulo: Hucitec. p. 62-74.

LABORATÓRIO de Geoprocessamento Aplicado - LGA; Departamento de Geografia e Meio Ambiente - GEM; Centro de Ciências Exatas e Naturais-CCEN \& Universidade Federal de Alagoas - Ufal. 2004. Mapa de localização da cidade de Maceió. Maceió, 1 mapa. Escalas variam.

LUCHIARI, M. T. D. P. 2000. Urbanização turística: um novo nexo entre o lugar e o mundo. In: SERRANO, C.; BRUHNS, H. T. \& LUCHIARI, M. T. D. P.(Orgs.). Olhares contemporâneos sobre o turismo. Campinas, sP: Papirus. p.17-36.

MACEIÓ. Decreto municipal no 5.569, de 22 de novembro de 1996. Disponível em: <http:// www.gw3-al.com.br/>. Acesso em 22 ago. 2003.

Maceió, fev.

Prefeitura Municipal. 1995. Plano Setorial de Desenvolvimento Urbano de Jaraguá.

MOESCH, M. M. 2000. A produção do saber turístico. São Paulo: Contexto.
PASCUAL Arquitetos Associados. 1996/1997. Revitalização da Vila dos Pescadores. Projeto Arquitetônico. Jaraguá, Maceió-AL.

PEDROSA, J. F. M. 1998. Histórias do velho Jaraguá. Maceió: Talento.

PROJETO de revitalização do bairro de Jaraguá. Disponível em: <http://www.gw3-al.com.br/ >. Acesso em 22 ago. 2003.

RODRIGUES, A. A. B. 2001. Percalços do planejamento turístico: o prodetur/Ne. In: RODRIGUES, A.A.B. (Org.). Turismo e geografia: reflexões teóricas e enfoques regionais. 3. ed. São Paulo: Hucitec. p. 147-162.

OLIVEIRA, A. U. 2000. A mundialização do capitalismo e a geopolítica mundial no fim do século xx. In: ROSS, J. L. (Org.). Geografia do Brasil. 3. ed. São Paulo: Ed. Universidade de São Paulo. p. 239-287.

OLIVEIRA, P. S. 2001. Introdução à sociologia. 24. ed. São Paulo: Ática.

TECNOLOGIA E CONSULTORIA BRASILEIRA S.A. - TC/BR. 1996. O PRODETUR-NE e sua importância para o municipio de Maceió. Maceió: TC/BR, abr.

SERPA, A. 2002. A paisagem periférica. In: YÁZIGI, E. (Org.). Turismo e paisagem. São Paulo: Contexto. p. 161-179.

Recebido em 30/03/2004 (1 ${ }^{\mathbf{a}}$ versão) e 09/09/2004 (2a versão). Aprovado em 06/10/2004. 